\title{
Analysis of Surface Roughness and Cutting Forces in Hard Turning of 42CrMo4 Steel using Taguchi and RSM Method
}

\author{
Mustafa ÖZDEMIR*, Mehmet Tuncay KAYA**, Hamza Kemal AKYILDIZ*** \\ *Department of Machine and Metal Technology, Vocational School of Technical Sciences, Yozgat Bozok University, \\ Yozgat, Turkey, E-mail: mustafa.ozdemir@bozok.edu.tr \\ **Department of Mechanical Engineering, Yozgat Bozok University, Yozgat, Turkey, E-mail: mtuncaykaya@gmail.com \\ ***Department of Mechanical Engineering, Yozgat Bozok University, Yozgat, Turkey, \\ E-mail: hkemal.akyildiz@bozok.edu.tr
}

cross $^{\text {ref }}$ http://dx.doi.org/10.5755/j01.mech.26.3.23600

\section{Introduction}

$42 \mathrm{CrMo} 4$ steel is alloy structural steels which are suitable for hardening in terms of carbon content and show high toughness under certain loads at the end of the tempering process. Therefore, machining is more difficult compared to alloy steels. The most important feature is that it can form a rigid martensitic structure after quenching due to $\mathrm{Cr}$ and Mo alloy elements it contains and it allows having mechanical properties such as strength, ductility and toughness, simultaneously. For all these reasons, $42 \mathrm{CrMo} 4$ steel is alloy structural steels that are always widely used. Among its main usage areas, they are used in the automobile and aircraft construction and the manufacturing of parts and gear wheels with high ductility such as crankshaft, axle shaft and housing, grooved shaft and etc. [1-3].

When examining the studies in literature, many studies are found. In their study, Özel et al., examined experimentally the impacts of cutting-edge geometry, workpiece hardness, feed rate and cutting speed on surface roughness and cutting forces in the finish hard turning of AISI H13 steel [7]. Panzera et al., investigated the effect of cutting parameters on cutting force in dry turning of AISI 4340 steel by using coated carbide tips. In addition, the effects of cutting parameters on cutting force were investigated with the results of Variance (ANOVA) analysis [8]. Singh and Rao investigated the surface roughness behaviour of tool geometry and cutting conditions in finish hard turning process for AISI 52100 (58 HRC) material. They used ANOVA in the analysis [9]. Jayant and Kumar used hardened steel AISI 4140 carbide as the test material. They found the most appropriate cutting parameters by evaluating the data with the help of ANOVA and Taguchi Method [10]. Derakhshan and Akbari investigated the effect of workpiece hardness and cutting speed of AISI 4140 material on surface roughness in the process of machining with CBN tool in hard turning process [11]. Chavoshi and Tajdari observed the change of $R a$ value by machining AISI 4140 steel with hard turning process with CBN cutting edge with hardness and cutting speed variables [12]. Yallese et al., determined the statistical models of cutting forces in dry turning process of AISI H11 hot working tool steel (50 HRC). They formed the mathematical models with multiple linear regression and Response Surface Methodology (RSM) and determined the most effective cutting parameters on cutting forces [13]. Suresh et al. in- vestigate the effect of cutting parameters (cutting speed, feed rate, depth of cut and cutting time) in turning of AISI 4340 hardened steel on cutting forces, tool wear and surface roughness by using RSM [14]. Abou-El-Hosseinb et al., conducted an experimental study for the estimation of forces occurring during the machining of AISI P20 tool steel. They evaluated the effects of four input parameters on cutting force by using RSM [15]. Yang et al., investigated the test results obtained by using cutting parameters such as cutting speed, feed rate, and depth of cut for finish turning of Titanium alloy (TC 11) material with RSM [16]. Asiltürk and Akkuş investigated the effect of cutting parameters on surface roughness ( $R a$ and $R z$ ) in hard turning processes by using Taguchi method [17]. Günay and Yücel conducted the optimization of surface roughness values obtained in machining of high alloy casting materials (50 HRC and 62 HRC) under cutting conditions (cutting speed, feed rate and depth of cut). Optimal conditions were determined using $S / N$ ratio [18]. Bouacha et al., conducted a study on the statistically analysis of surface roughness and cutting forces using RSM in hard turning of AISI 52100 bearing steel. The effect of cutting forces and cutting parameters affecting surface roughness was analysed by ANOVA [19]. Lalwani et al., conducted an experimental study on the effect of cutting parameters (cutting speed, feed rate and depth of cut) on cutting forces and surface roughness in finish hard turning of MDN250 steel [20]. In their study, Agrawal et al., studies the estimation of surface roughness during hard turning of AISI 4340 steel [21].

In this study, the effect of cutting parameters on surface roughness and cutting forces were investigated during the machining of high hardness $42 \mathrm{CrMo} 4$ alloy structural steel with ceramic insert having different tip radiuses. During the experiments, the interactions between the cutting parameters and the effects of the parameters on cutting force $(F x, F y$ and $F z)$ and surface roughness ( $R a$, $R z$ and $R t$ ) were focused. In this research, optimization of cutting parameters (cutting speed, feedrate, cutting depth and tool radius) was made by using Taguchi L18 composite orthogonal array. Using Taguchi method, optimum surface roughness and cutting forces values were determined and the relationship between the parameters was investigated. In addition, the effects of control factors on surface roughness and cutting forces were determined by ANOVA. Finally, the validity of the optimization was tested by validation tests and the results of the experiments were evaluated. 


\section{Material and method}

For the hard finish turning processes of hardened 42CrMo4 (52 HRC) material in CNC lathe machine, three cutting speeds $(200,250$ and $300 \mathrm{~m} / \mathrm{min})$, three feed rates $(0.05,0.1$, and $0.15 \mathrm{~mm} / \mathrm{rev})$, three depths of chip $(0.1$, 0.25 and $0.4 \mathrm{~mm})$, and two tool tip radii $(0.8$ and $1.2 \mathrm{~mm})$ were used. An experimental study was conducted to investigate the effect of machining parameters on surface roughness $R a, R z$ and $R t$ and cutting forces $F x, F y$ and $F z$. Hard finish turning tests were carried out on GOODWAY GS-260/Y brand CNC turning lathe with maximum speed of $4500 \mathrm{rpm}$. In the machining tests, 42CrMo4 (52 HRC) material hardened to the core in the dimensions of Ø80x560 mm was used. Table 1 shows the chemical composition of the test material used.

Table 1

Chemical and mechanical properties of test material $42 \mathrm{CrMo} 4$ steel

\begin{tabular}{|c|c|c|c|c|c|c|c|c|}
\hline $\mathrm{Fe}$ & Co & $\mathrm{Nb}$ & $\mathrm{Si}$ & $\mathrm{Cr}$ & $\mathrm{Ni}$ & $\mathrm{Ti}$ & $\mathrm{Al}$ & $\mathrm{Cu}$ \\
\hline 96.948 & 0.009 & 0.005 & 0.290 & 0.953 & 0.164 & 0.002 & 0.012 & 0.181 \\
\hline $\mathrm{P}$ & $\mathrm{V}$ & $\mathrm{Mn}$ & $\mathrm{Pb}$ & W & $\mathrm{C}$ & Mo & $\mathrm{S}$ & \\
\hline 0.008 & 0.006 & 0.788 & 0.001 & 0.002 & 0.424 & 0.187 & 0.022 & \\
\hline \multicolumn{9}{|c|}{ Mechanical Properties } \\
\hline \multicolumn{2}{|c|}{ Yield Strength, N/mm² } & \multicolumn{3}{|c|}{ Tensile Strength, N/mm² } & \multicolumn{2}{|c|}{ Rupture Strength, N/mm² } & \multicolumn{2}{|c|}{ Poisson Ratio } \\
\hline \multicolumn{2}{|c|}{1058.95} & \multicolumn{3}{|c|}{1159.19} & \multicolumn{2}{|c|}{798.23} & \multicolumn{2}{|c|}{0.29} \\
\hline
\end{tabular}

In the study, Kennanetal TNGA 160408 and TNGA 160412 KY1615 type uncoated ceramic tips were preferred. Cutting tool catalogue was used to determine the cutting parameters of the tools. Prior to the experiment, cuttings were made in the catalogue values so that a preliminary assessment opportunity was obtained. Coolant was not used in the study. Fig. 1 The system used in turning tests.

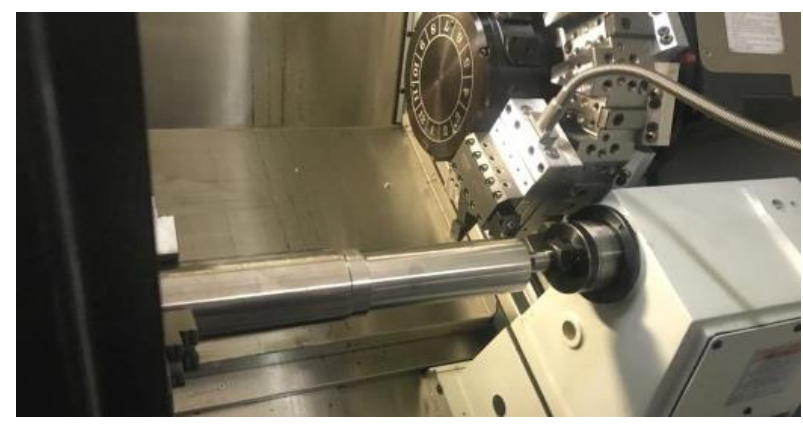

Fig. 1 The system for optimization of cutting parameters

Taguchi method is an effective analysis method used to optimize the machining parameters affecting the production process. With the experimental design made by using this method, the number of experiments is significantly reduced and the time losses are minimized. In the study, the experimental design was made with Taguchi method and surface roughness $R a, R z$ and $R t$ and cutting forces $F x, F y$ and $F z$ were taken as a basis for quality features. Control factors were determined as cutting speed $(\mathrm{m} / \mathrm{min})$, feed rate $(\mathrm{mm} / \mathrm{rev})$, depth of cut $(\mathrm{mm})$ and tool tip radius $(\mathrm{mm})$. As control factors, Taquchi $L 18$ (2x1, $3 \times 3$ ) mixed orthogonal array was used. Table 2 shows control factors and their levels.

Table 2

Control factors for design of experimentation

\begin{tabular}{|l|l|l|l|}
\hline Parameters & Level 1 & Level 2 & Level 3 \\
\hline Cutting speed, $V$ & 200 & 250 & 300 \\
\hline Feed rate, $f$ & 0,05 & 0,1 & 0,15 \\
\hline Depth of cut, $a$ & 0,1 & 0,25 & 0,4 \\
\hline Tool nose radius, $R$ & 0,8 & 1,2 & \\
\hline
\end{tabular}

Since conducting a total of $27 \times 2=54$ experiments with full factorial design would cause loss in terms of cost and time, $L 18(2 \times 1,3 \times 3)$ mixed orthogonal array was made with Taguchi method in order to eliminate these problems. When the time and material costs of these tests are evaluated, the method developed by Taguchi responds to the need by reducing the number of experiments [22].

In the study, Taguchi method was used as experimental design and analysis method. A statistical performance measure known as the $S / N$ ratio is used to analyse the test results. The results obtained from the tests are evaluated by converting them to the signal to noise ratio $(S / N)$. In $S / N$ ratio, $S$ and $N$ refer to the signal factor and noise factor, respectively. The signal factor refers to the real value taken from the system and the noise factor refer to the factors that cannot be included in the test design but affect the test results. In the calculation of $S / N$ ratios, the methods of "the nominal is the best", "the larger is better", and "the smaller is better" are used depending on the characteristic type.

Since surface roughness value was desired to be the smallest in the determination of $S / N$ values in this study, the formula corresponding to the principle of "the smaller is better" given in Eq.(1) was used [23-25].

$$
\frac{S}{N}=-10 * \log \left(\frac{1}{n} \sum_{i=1}^{n} Y i^{2}\right) .
$$

In order to determine the effect of control factors on cutting forces and surface roughness values, ANOVA analysis was applied to the test results at confidence interval of $95 \%$. Taguchi method and ANOVA analysis were performed using Minitab16 program. The experimental design was made by using Taguchi L18 mixed orthogonal array with main machining parameters in Table 3. Table 3 shows the Taguchi $L 18$ experiment design prepared with Minitab 16 software.

The average surface roughness $R a, R z$ and $R t$ values were measured using the Mahr MarSurf PS10 brand and model surface roughness measuring device in accordance with ISO 4287 standard. In the measurement of cutting forces generated during the machining of $42 \mathrm{CrMo} 4$ material, a KİSTLER 9129AA-Kistler TYPE 5070 piezoelectric-based dynamometer which can 
simultaneously measure three force components $F x, F y, F z$ was used. After the measurements, surface roughness and cutting force values were obtained by taking arithmetic mean of the values.

\section{Results and analysis}

In Taguchi mixed orthogonal array, $S / N$ ratios are used to determine the optimum levels of control factors. Table 3 and Table 4 show the surface roughness and cutting force values obtained during the machining of $42 \mathrm{CrMo} 4$ material on the $\mathrm{CNC}$ turning lathe and $\mathrm{S} / \mathrm{N}$ ratios obtained with the function of "the smaller is better", respectively.

The $S / N$ response table is used to analyse the effect of each control factor on surface roughness. Table 3 shows the $S / N$ response table obtained as a result of the analysis. It shows the optimum levels of control factors for optimum surface roughness values determined by using Taguchi technique. The best level for control factors was found based on the highest $S / N$ ratio in all levels of those control factors. Accordingly, the levels and $S / N$ ratios of the factors giving the best $R a$ value were determined as factor $V$ (Level 3, $S / N=9.488$ ), factor $f$ (Level 1 , $S / N=13.124)$, factor $a$ (Level $1, S / N=8.167)$, and factor $R$ (Level 2, $S / N=9.395)$. In other words, the optimum $R a$ value was obtained with $300 \mathrm{~m} / \mathrm{min}$ cutting speed (V3), $0.05 \mathrm{~mm} / \mathrm{rev}$ feed rate $(f 1), 0.1 \mathrm{~mm}$ depth of cut $(a 1)$ and $1.2 \mathrm{~mm}$ tool tip radius ( $R 2)$ (Fig. 2, a). When Table 5 is examined, the most effective control factors on $R a$ were determined in significance order as feed rate, tool tip radius, cutting speed, and depth of cut.

Table 3

$L 18$ (2x1 3x3) mixed orthogonal array, experimental results and their $S / N$ ratios for $R a, R z$ and $R t$

\begin{tabular}{|c|c|c|c|c|c|c|c|c|c|c|}
\hline \multirow{2}{*}{$\begin{array}{c}\text { Trial } \\
\text { Number }\end{array}$} & \multicolumn{4}{|c|}{ Main machining parameters } & \multicolumn{2}{c|}{ Measured surface roughness values } & \multicolumn{3}{c|}{$S / N$ ratio } \\
\cline { 2 - 11 } & $V, \mathrm{~m} / \mathrm{min}$ & $f, \mathrm{~mm} / \mathrm{rev}$ & $a, \mathrm{~mm}$ & $R, \mathrm{~mm}$ & $R a, \mu \mathrm{m}$ & $R z, \mu \mathrm{m}$ & $R t, \mu \mathrm{m}$ & $R a, \mathrm{~dB}$ & $R z, \mathrm{~dB}$ & $R t, \mathrm{~dB}$ \\
\hline 1 & 200 & 0,15 & 0,4 & 0,8 & 1,245 & 5,077 & 5,359 & $-1,9034$ & $-14,1121$ & $-14,5817$ \\
\hline 2 & 200 & 0,1 & 0,25 & 0,8 & 0,619 & 3,077 & 3,294 & 4,1662 & $-9,7625$ & $-10,3545$ \\
\hline 3 & 200 & 0,05 & 0,1 & 0,8 & 0,245 & 1,869 & 2,049 & 12,2167 & $-5,4322$ & $-6,2308$ \\
\hline 4 & 250 & 0,15 & 0,4 & 0,8 & 0,966 & 4,264 & 4,319 & 0,3005 & $-12,5963$ & $-12,7077$ \\
\hline 5 & 250 & 0,1 & 0,25 & 0,8 & 0,457 & 2,352 & 2,477 & 6,8017 & $-7,4287$ & $-7,8785$ \\
\hline 6 & 250 & 0,05 & 0,1 & 0,8 & 0,237 & 1,598 & 1,704 & 12,5050 & $-4,0715$ & $-4,6294$ \\
\hline 7 & 300 & 0,1 & 0,4 & 0,8 & 0,421 & 2,51 & 2,707 & 7,5144 & $-7,9935$ & $-8,6498$ \\
\hline 8 & 300 & 0,05 & 0,25 & 0,8 & 0,184 & 1,309 & 1,458 & $\mathbf{1 4 , 7 0 3 6}$ & $-2,3388$ & $-3,2752$ \\
\hline 9 & 300 & 0,15 & 0,1 & 0,8 & 0,893 & 4,097 & 4,197 & 0,9830 & $-12,2493$ & $-12,4588$ \\
\hline 10 & 200 & 0,05 & 0,4 & 1,2 & 0,201 & 1,599 & 2,144 & 13,9361 & $-4,0770$ & $-6,6245$ \\
\hline 11 & 200 & 0,15 & 0,25 & 1,2 & 0,532 & 2,313 & 2,447 & 5,4818 & $-7,2835$ & $-7,7727$ \\
\hline 12 & 200 & 0,1 & 0,1 & 1,2 & 0,56 & 2,669 & 2,794 & 5,0362 & $-8,5270$ & $-8,9245$ \\
\hline 13 & 250 & 0,1 & 0,4 & 1,2 & 0,292 & 1,908 & 1,96 & 10,6923 & $-5,6116$ & $-5,8451$ \\
\hline 14 & 250 & 0,05 & 0,25 & 1,2 & 0,276 & 1,665 & 1,84 & 11,1818 & $-4,4283$ & $-5,2964$ \\
\hline 15 & 250 & 0,15 & 0,1 & 1,2 & 0,596 & 2,51 & 2,606 & 4,4951 & $-7,9935$ & $-8,3195$ \\
\hline 16 & 300 & 0,05 & 0,4 & 1,2 & 0,195 & 1,273 & 1,397 & 14,1993 & $\mathbf{- 2 , 0 9 6 6}$ & $\mathbf{- 2 , 9 0 3 9}$ \\
\hline 17 & 300 & 0,15 & 0,25 & 1,2 & 0,515 & 2,514 & 2,652 & 5,7639 & $-8,0073$ & $-8,4715$ \\
\hline 18 & 300 & 0,1 & 0,1 & 1,2 & 0,205 & 1,442 & 1,599 & 13,7649 & $-3,1793$ & $-4,0770$ \\
\hline
\end{tabular}

Table 4

$L 18$ (2x1 3x3) mixed orthogonal array, experimental results and their $S / N$ ratios for Cutting Force

\begin{tabular}{|c|c|c|c|c|c|c|c|c|c|c|}
\hline \multirow{2}{*}{$\begin{array}{c}\text { Trial } \\
\text { Number }\end{array}$} & \multicolumn{4}{|c|}{ Main machining parameters } & \multicolumn{2}{c|}{ Measured cutting force values } & \multicolumn{3}{c|}{$S / N$ ratio } \\
\cline { 2 - 11 } & $V, \mathrm{~m} / \mathrm{min}$ & $f, \mathrm{~mm} / \mathrm{rev}$ & $a, \mathrm{~mm}$ & $R, \mathrm{~mm}$ & $F x, \mathrm{~N}$ & $F y, \mathrm{~N}$ & $F z, \mathrm{~N}$ & $F x, \mathrm{~dB}$ & $F y, \mathrm{~dB}$ & $F z, \mathrm{~dB}$ \\
\hline 1 & 200 & 0,15 & 0,4 & 0,8 & 199,40 & 225,60 & 157,50 & $-45,9945$ & $-47,0668$ & $-43,9456$ \\
\hline 2 & 200 & 0,1 & 0,25 & 0,8 & 112,90 & 107,90 & 86,44 & $-41,0539$ & $-40,6604$ & $-38,7343$ \\
\hline 3 & 200 & 0,05 & 0,1 & 0,8 & 27,92 & 24,55 & 35,75 & $-\mathbf{2 8 , 9 1 8 3}$ & $-\mathbf{2 7 , 8 0 1 0}$ & $-31,0655$ \\
\hline 4 & 250 & 0,15 & 0,4 & 0,8 & 223,90 & 230,90 & 187,40 & $-47,0011$ & $-47,2685$ & $-45,4554$ \\
\hline 5 & 250 & 0,1 & 0,25 & 0,8 & 123,10 & 116,60 & 108,20 & $-41,8052$ & $-41,3340$ & $-40,6845$ \\
\hline 6 & 250 & 0,05 & 0,1 & 0,8 & 30,00 & 24,56 & 35,54 & $-29,5424$ & $-27,8011$ & $-\mathbf{3 1 , 0 1 4 3}$ \\
\hline 7 & 300 & 0,1 & 0,4 & 0,8 & 137,10 & 163,60 & 139,10 & $-42,7407$ & $-44,2757$ & $-42,8665$ \\
\hline 8 & 300 & 0,05 & 0,25 & 0,8 & 62,58 & 65,92 & 69,76 & $-35,9287$ & $-36,3803$ & $-36,8721$ \\
\hline 9 & 300 & 0,15 & 0,1 & 0,8 & 60,90 & 69,29 & 42,24 & $-35,6923$ & $-36,8134$ & $-32,5145$ \\
\hline 10 & 200 & 0,05 & 0,4 & 1,2 & 84,56 & 91,71 & 76,62 & $-38,5433$ & $-39,2483$ & $-37,6868$ \\
\hline 11 & 200 & 0,15 & 0,25 & 1,2 & 129,70 & 151,70 & 81,47 & $-42,2588$ & $-43,6197$ & $-38,2200$ \\
\hline 12 & 200 & 0,1 & 0,1 & 1,2 & 69,41 & 70,83 & 44,23 & $-36,8284$ & $-37,0043$ & $-32,9143$ \\
\hline 13 & 250 & 0,1 & 0,4 & 1,2 & 128,00 & 161,20 & 99,83 & $-42,1442$ & $-44,1473$ & $-39,9852$ \\
\hline 14 & 250 & 0,05 & 0,25 & 1,2 & 64,63 & 67,13 & 55,53 & $-36,2087$ & $-36,5383$ & $-34,8906$ \\
\hline 15 & 250 & 0,15 & 0,1 & 1,2 & 69,01 & 76,73 & 44,76 & $-36,7782$ & $-37,6993$ & $-33,0178$ \\
\hline 16 & 300 & 0,05 & 0,4 & 1,2 & 87,95 & 94,26 & 78,13 & $-38,8847$ & $-39,4865$ & $-37,8564$ \\
\hline 17 & 300 & 0,15 & 0,25 & 1,2 & 117,00 & 139,00 & 74,56 & $-41,3637$ & $-42,8603$ & $-37,4501$ \\
\hline 18 & 300 & 0,1 & 0,1 & 1,2 & 42,39 & 44,36 & 36,24 & $-32,5453$ & $-32,9398$ & $-31,1838$ \\
\hline
\end{tabular}


Table 5

Table 8

Response table for signal to noise ratios for $R a$

\begin{tabular}{|l|c|c|c|c|c|}
\hline Factors & Level 1 & Level 2 & Level 3 & Delta $(\delta)$ & Rank \\
\hline$V$ & 6,489 & 7,663 & $\mathbf{9 , 4 8 8}$ & 2,999 & 3 \\
\hline$f$ & $\mathbf{1 3 , 1 2 4}$ & 7,996 & 2,520 & 10,604 & 1 \\
\hline$a$ & $\mathbf{8 , 1 6 7}$ & 8,016 & 7,457 & 0,710 & 4 \\
\hline$R$ & 6,365 & $\mathbf{9 , 3 9 5}$ & & 3,029 & 2 \\
\hline
\end{tabular}

Table 6

Response table for signal to noise ratios for $R z$

\begin{tabular}{|l|c|c|c|c|c|}
\hline Factors & Level 1 & Level 2 & Level 3 & Delta $(\delta)$ & Rank \\
\hline$V$ & $-8,199$ & $-7,022$ & $\mathbf{- 5 , 9 7 7}$ & 2,222 & 3 \\
\hline$f$ & $\mathbf{- 3 , 7 4 1}$ & $-7,084$ & $-10,374$ & 6,633 & 1 \\
\hline$a$ & $-6,909$ & $\mathbf{- 6 , 5 4 2}$ & $-7,748$ & 1,206 & 4 \\
\hline$R$ & $-8,443$ & $\mathbf{- 5 , 6 8 9}$ & & 2,753 & 2 \\
\hline
\end{tabular}

Table 7

Response table for signal to noise ratios for $R t$

\begin{tabular}{|l|c|c|c|c|c|}
\hline Factors & Level 1 & Level 2 & Level 3 & Delta $(\delta)$ & Rank \\
\hline$V$ & $-9,081$ & $-7,446$ & $\mathbf{- 6 , 6 3 9}$ & 2,442 & 3 \\
\hline$f$ & $\mathbf{- 4 , 8 2 7}$ & $-7,622$ & $-10,719$ & 5,892 & 1 \\
\hline$a$ & $-7,440$ & $\mathbf{- 7 , 1 7 5}$ & $-8,552$ & 1,377 & 4 \\
\hline$R$ & $-8,974$ & $\mathbf{- 6 , 4 7 1}$ & & 2,503 & 2 \\
\hline
\end{tabular}

The effect of the control parameters on $R z$ and $R t$ was determined according to the $S / N$ ratios. Tables 6 and 7 show the effect level of each factor on $R z$ and $R t$. (Fig. 2, b) and (Fig. 2, c) show that $3^{\text {rd }}$ level of cutting speed, $1^{\text {st }}$ level of feed rate, $2^{\text {nd }}$ level of depth of cut and tool tip radius are
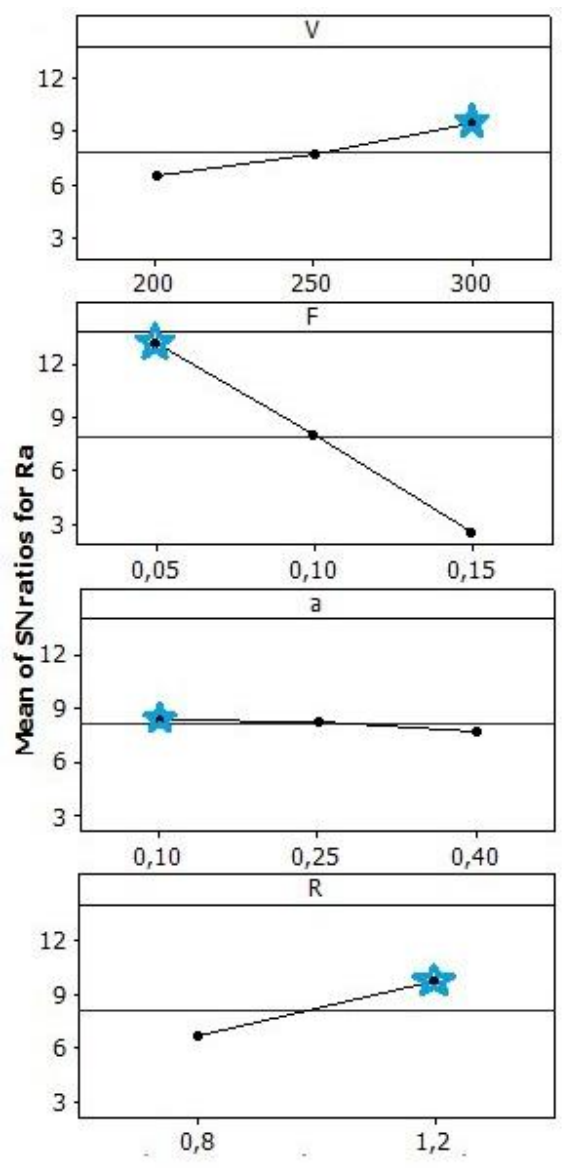

a
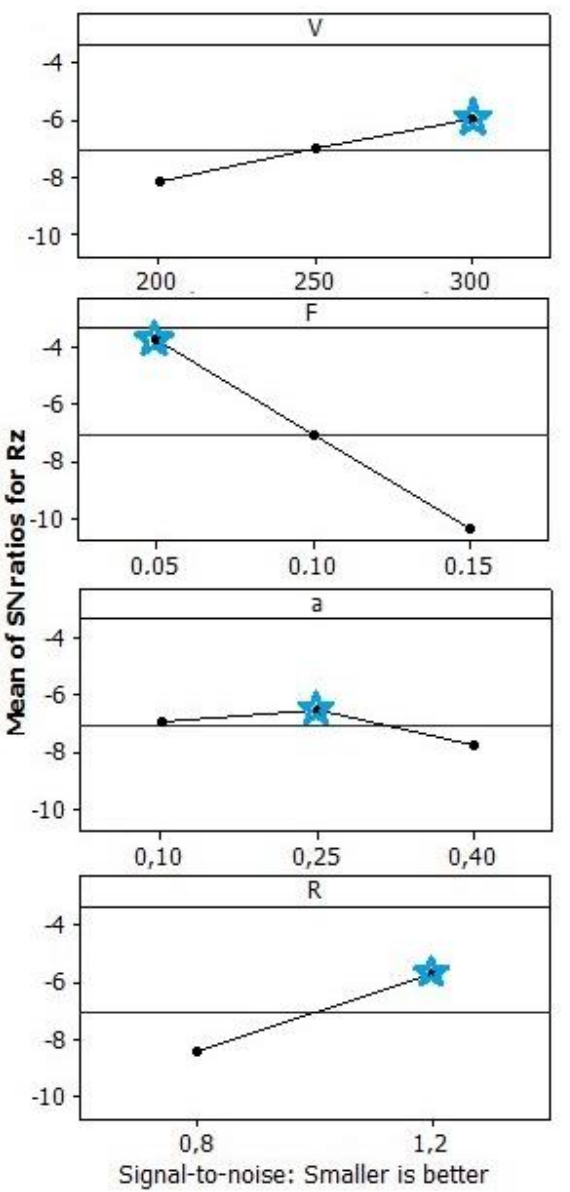

Signal-to-noise: Smaller is better

b
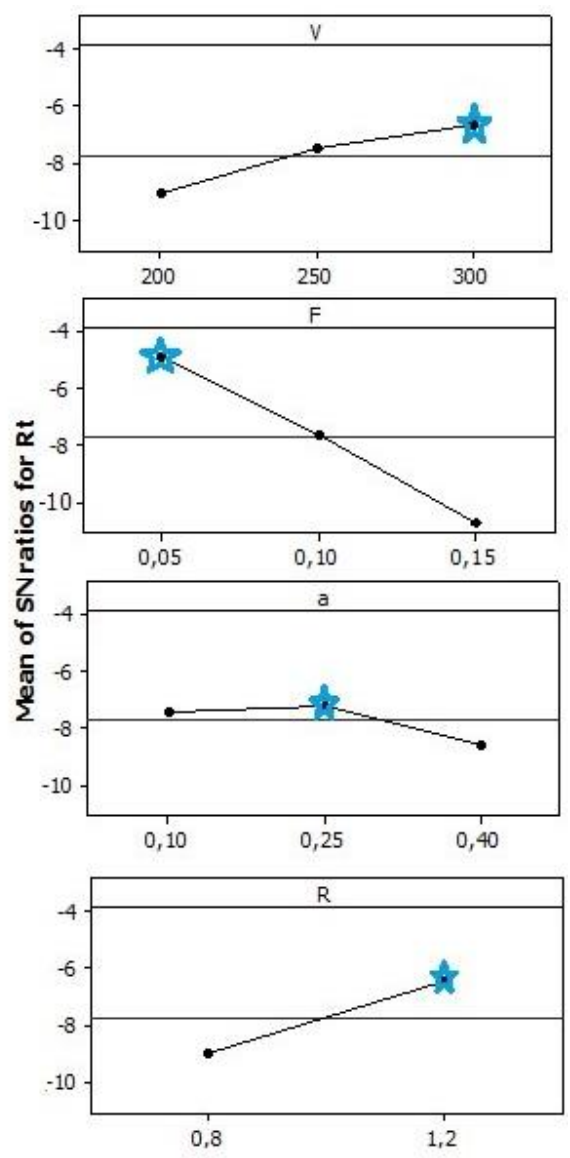

c

Fig. 2 Main effect plots for $S / N$ ratio for surface roughness ( $a=R a, b=R z ; c=R t)$ 
Fig. 3 shows the surface graphs showing the effects of the machining parameters $f, R, a$ and $V$ on surface roughness. By increasing $f$, the most effective parameter on surface roughness, the amount of chips that need to be removed by the cutter in one cycle increases. Thus, the surface quality deteriorates. In order to obtain low surface roughness in finishing processes, the most effective method is to reduce $f[26,27]$. In this context, the increase in $R a, R z$ and $R t$ values on the surface with the increase of $f$ is an expected result (Figs. 3, a - c). Therefore, it was determined that there was a direct correlation between surface roughness and $f$. This result supports the evaluation made according to $S / N$ ratios and is in parallel with the theoretical formula $R a=0.321 f^{2} / R$ pointing out that the surface roughness value will increase proportionally with the square of " $f$ ".

It is seen that $R a, R z$ and $R t$ tend to decrease with the increasing tool radius $R$ (Figs. 3, a-c). This result can be explained by chip formation depending on uncut chip thickness decreasing with the increase of $R$. Based on the increase in cutting tool radius, it was emphasized that the uncut chip thickness would decrease along the cutting edge due to the increase in cutting tool radius [26]. It was determined that the cutting speed was not as effective as feed rate and tool tip radius on surface roughness. (Figs. 3, $\mathrm{d}-\mathrm{f}$ ) show that there was a decrease in surface roughness values with the decreased depth of cut.

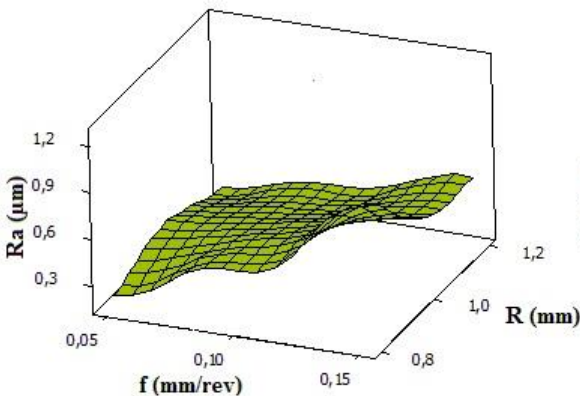

a

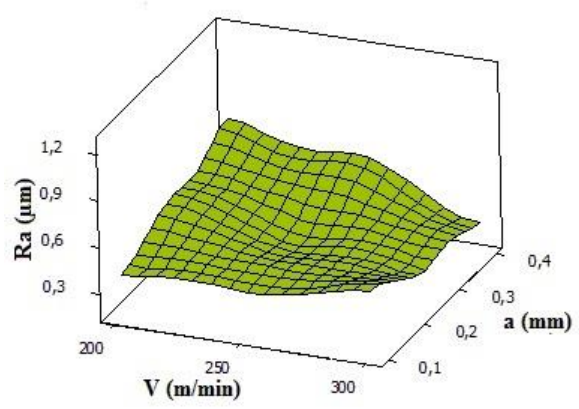

d

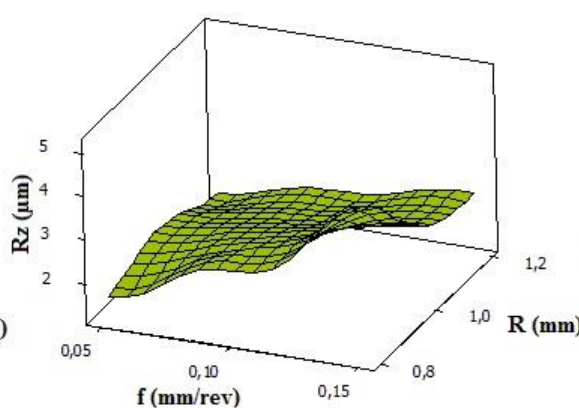

b

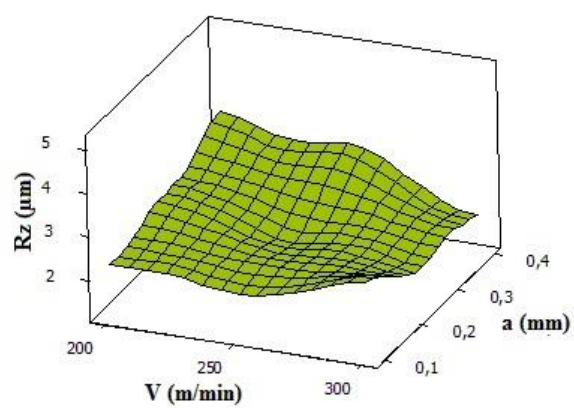

$\mathrm{e}$

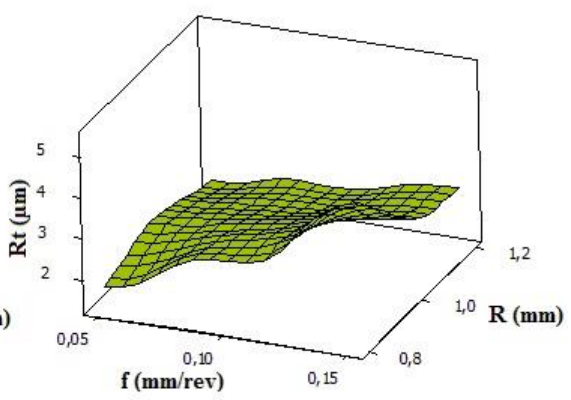

c

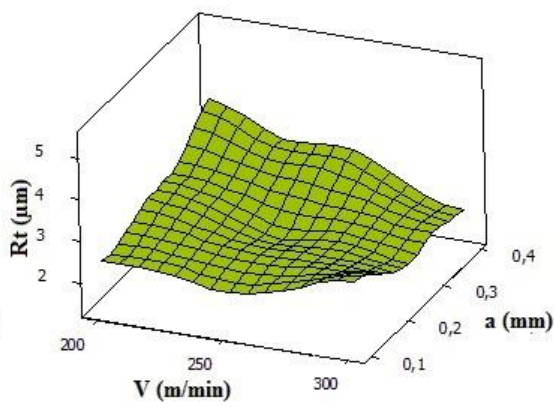

f

Fig. 3 Effect of machining parameters on $R a, R z$ and $R t$

The effects of control factors on cutting forces $F x$, $F y$, and $F z$ were determined with $S / N$ ratios in Table 4. Table 8 and Table 10 show the individual effects of the levels of these control factors on cutting forces. When examining Table 8 and Table 10, it was determined that $3^{\text {rd }}$ level of cutting force $V 3,2^{\text {nd }}$ level of tool tip radius $R 2$, and $1^{\text {st }}$ level of the feeding rate $f 1$ and depth of cut a1 were effective on $F x$ and $F z$ forces $V 3-R 2-f 1-a 1.3^{\text {rd }}$ level of cutting speed and $1^{\text {st }}$ level of feeding rate, depth of cut and tool tip radius factors were found to be effective on $F y$ force $V 3-f 1-a 1-R 1$ (Table 9).

When $S / N$ values giving the effect of $F x$ average by factors in (Fig. 4, a) were examined, the most effective parameter on $F x$ was found to be depth of cut. Changes in other factors (from big to small) are listed as feeding rate, cutting speed, and tool tip radius. When (Fig. 4, b) and (Fig. 4, c) were examined, it was determined that feeding rate was the most effective on $F y$ and $F z$ forces and the impact level of the other parameters were listed from big to small as feeding rate, tool tip radius and cutting speed. When (Fig. 4) was examined, depth of cut and feeding rate were determined to be the most effective factors on $F x, F y$, and $F z$.
ANOVA was used to determine the effects of cutting parameters on cutting forces $F x, F y$ and $F z$ used in the experimental design. Table 11 shows the results of ANOVA performed at confidence interval of $95 \%$ for $F x$, $F y$, and $F z$. When Table 11 was examined, it was determined that $a$ and $f$ factors were significant and $R$ and $V$ were insignificant on $F x$ and $F y$ according to the significance value of $p<0.05$. It was determined that $a, f$, and $R$ were significant and $V$ was not significant on $F z$. It was determined that $a$, the most effective factor on $F x, F y$ and $F z$, gave contributions of $53.48 \%, 56.63 \%$, and $63.47 \%$, respectively. The second most effective factor $f$ affected $F x$ by $33.21 \%, F y$ by $36.18 \%$, and $F z$ by $14.22 \%$. The effect of the third most effective control factor $R$ on $F x, F y$ and $F z$ was determined as $3.88 \%, 1.52 \%$ and $12.40 \%$, respectively. Lastly, parameter $V$ which had the least effect among the control factors affected $F x$ by $2.28 \%, F y$ by $1.21 \%$ and lastly $F z$ by $0.45 \%$. When examining (Fig. 5), it was seen that the low effect of $V$ and $R$ on $F x, F y$ and $F z$ confirmed the ANOVA tables.

ANOVA was used to determine the effects of control factors on $R a, R z$ and Rt. Table 12 shows the results of ANOVA performed at the confidence interval of 
95\% for $R a, R z$ and $R t$. When examining Table 12, it was seen that while the parameters $V$ and $a$ were not effective on surface roughness in terms of significance value of $p<0.05, f, R$ and $R * f$ interaction was significant. The contribution rates in Table 11 show the significance level of control parameters on $R a, R z$, and $R t$. It was determined that $f$ was the most effective factor on $R a, R z$ and $R t$ with the contribution rates of $62.36 \%, 55.33 \%$ and $50.36 \%$, respectively. It was determined that $R$ which is the second most effective control factor contributed to $R a$ by $12.58 \%$, $R z$ by $19.16 \%$ and $R t$ by $18.58 \%$. The changes in other factors were listed as $V$ and a (from big to small). While the contribution rates of $V$ on $R a, R z$ and $R t$ were $5.25 \%$, $5.04 \%$ and $7.02 \%$, respectively, the factor $a$ which had the lowest effect affected $R a$ by $1.83 \%, R z$ by $2.52 \%$, and $R t$ by $3.64 \%$. The contribution rates of $R * f$ interaction on $R a$, $R z$, and $R t$ were determined as $8.49 \%, 9.67 \%$ and $10.76 \%$.
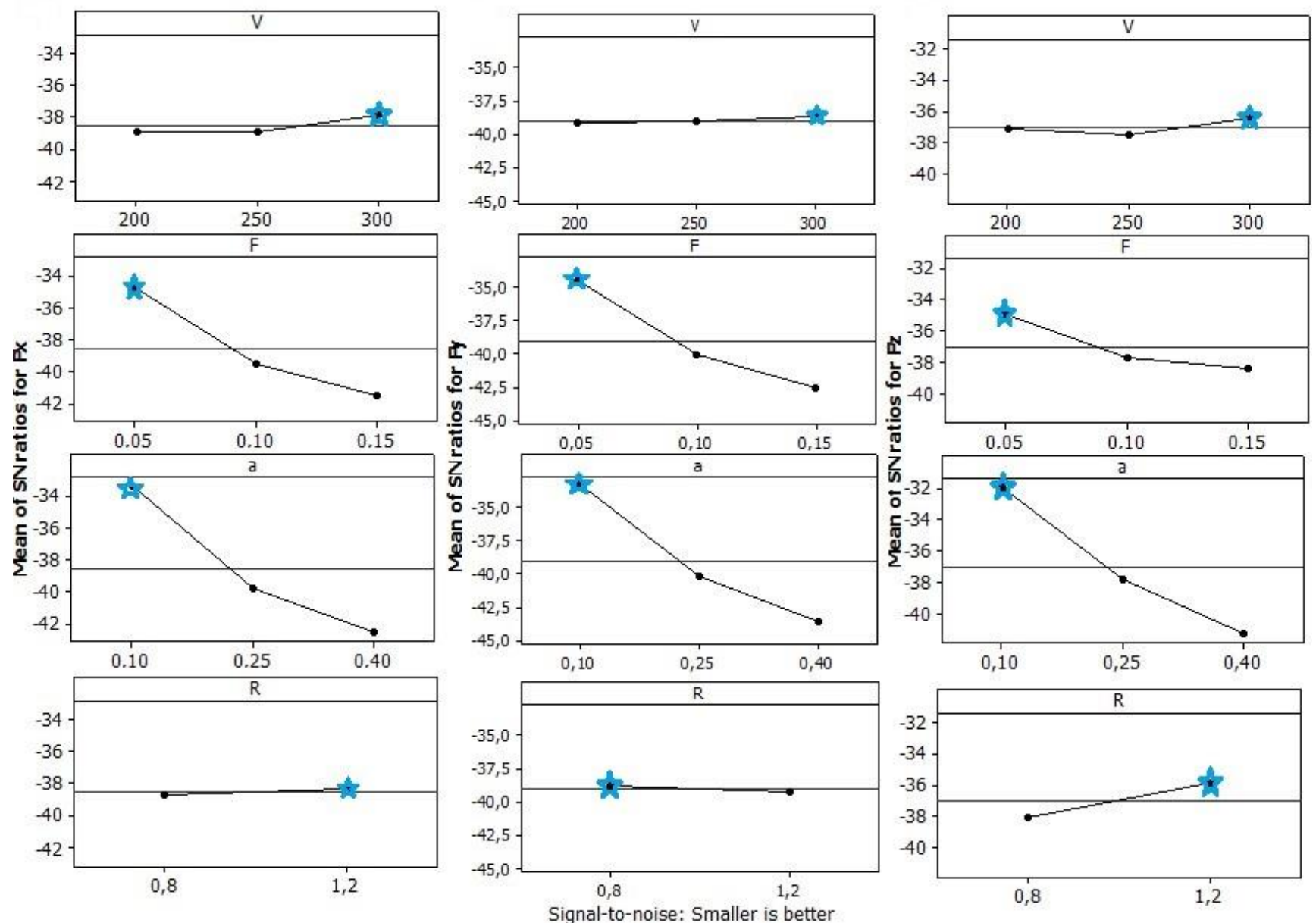

a

b

Fig. 4 Main effect plots for $S / N$ ratio for cutting force components $(a=F x ; b=F y ; c=F z)$

Analysis of variance for cutting force components

Table 11

Seq SS

\begin{tabular}{|c|c|c|c|c|c|c|c|}
\hline Source & DF & Seq SS & Adj SS & Adj MS & $F$ & $P$ & \% Cont. \\
\hline \multicolumn{8}{|c|}{ a) Analysis of variance for $F x$ (Radial force) } \\
\hline$R$ & 1 & 1904,5 & 340,5 & 340,5 & 2,17 & 0,215 & 3,88 \\
\hline V & 1 & 1120,8 & 362,3 & 362,3 & 2,30 & 0,204 & 2,28 \\
\hline$f$ & 1 & 16300,2 & 8768,1 & 8768,1 & 55,77 & 0,002 & 33,21 \\
\hline$a$ & 1 & 26252,9 & 12693,8 & 12693,8 & 80,73 & 0,001 & 53,48 \\
\hline$V^{*} V$ & 1 & 587,8 & 271,8 & 271,8 & 1,73 & 0,259 & 1,20 \\
\hline$f^{*} f$ & 1 & 129,4 & 4,3 & 4,3 & 0,03 & 0,876 & 0,26 \\
\hline$a * a$ & 1 & 97,6 & 234,5 & 234,5 & 1,49 & 0,289 & 0,20 \\
\hline$R * V$ & 1 & 156,3 & 0,0 & 0,0 & 0,00 & 0,992 & 0,32 \\
\hline$R * f$ & 1 & 25,8 & 356,4 & 356,4 & 2,27 & 0,207 & 0,05 \\
\hline$R^{*} a$ & 1 & 998,4 & 222,5 & 222,5 & 1,42 & 0,300 & 2,03 \\
\hline$V^{*} f$ & 1 & 26,2 & 20,3 & 20,3 & 0,13 & 0,738 & 0,05 \\
\hline$V^{*} a$ & 1 & 197,8 & 197,8 & 197,8 & 1,26 & 0,325 & 0,40 \\
\hline$f^{*} a$ & 1 & 662,2 & 662,2 & 662,2 & 4,21 & 0,109 & 1,35 \\
\hline Residual Error & 4 & 628,9 & 628,9 & 157,2 & & & 1,28 \\
\hline Total & 17 & 49088,8 & & & & & 100 \\
\hline \multicolumn{8}{|c|}{$R-S q=98,72 \% \quad R-S q(\operatorname{adj})=94,55 \%$} \\
\hline
\end{tabular}




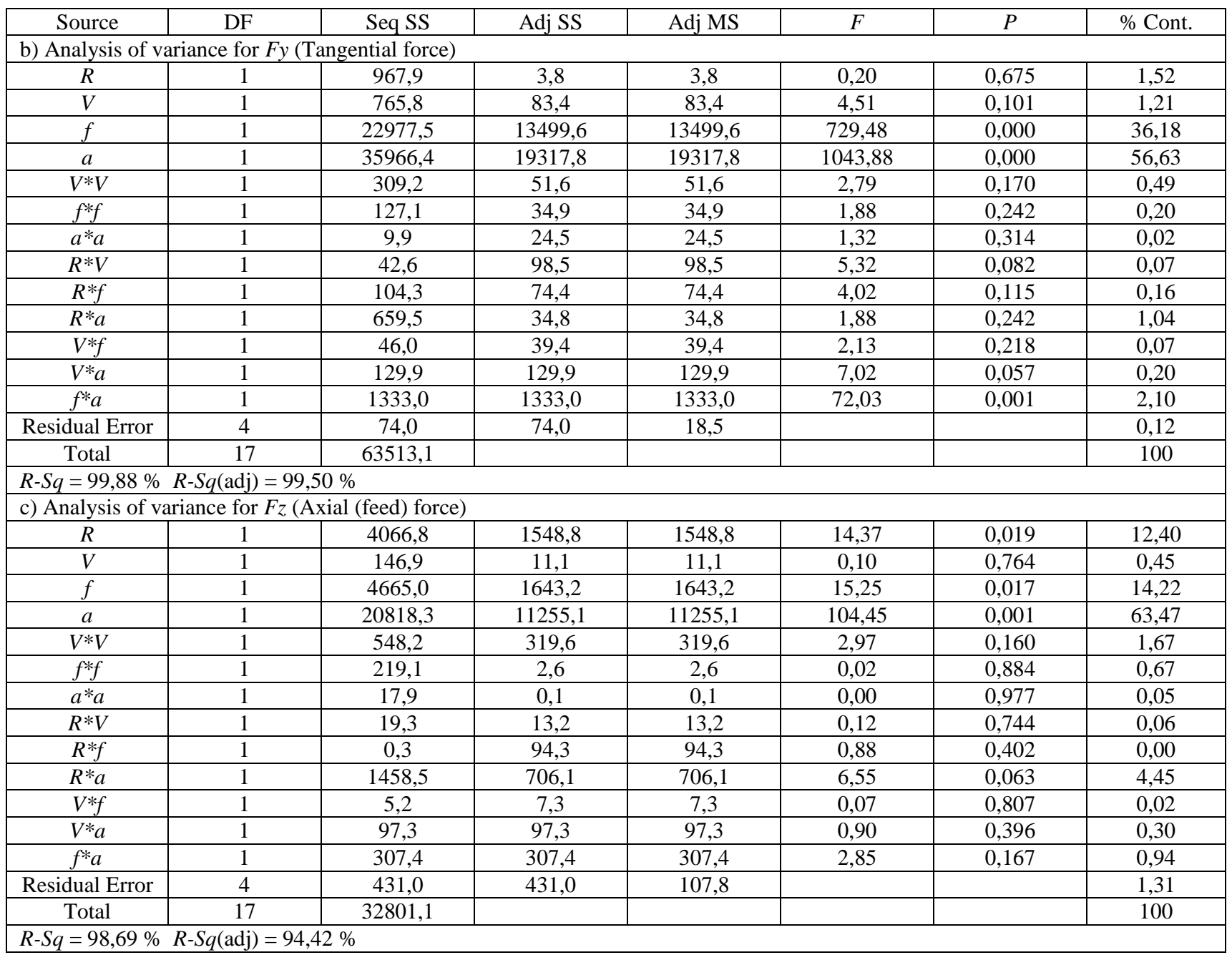

Analysis of variance for surface roughness components

Table 12

\begin{tabular}{l|l|l|l|l|l} 
Seq SS & Adj SS & Adj MS & $F$ & $P$ & $\%$ Cont.
\end{tabular}

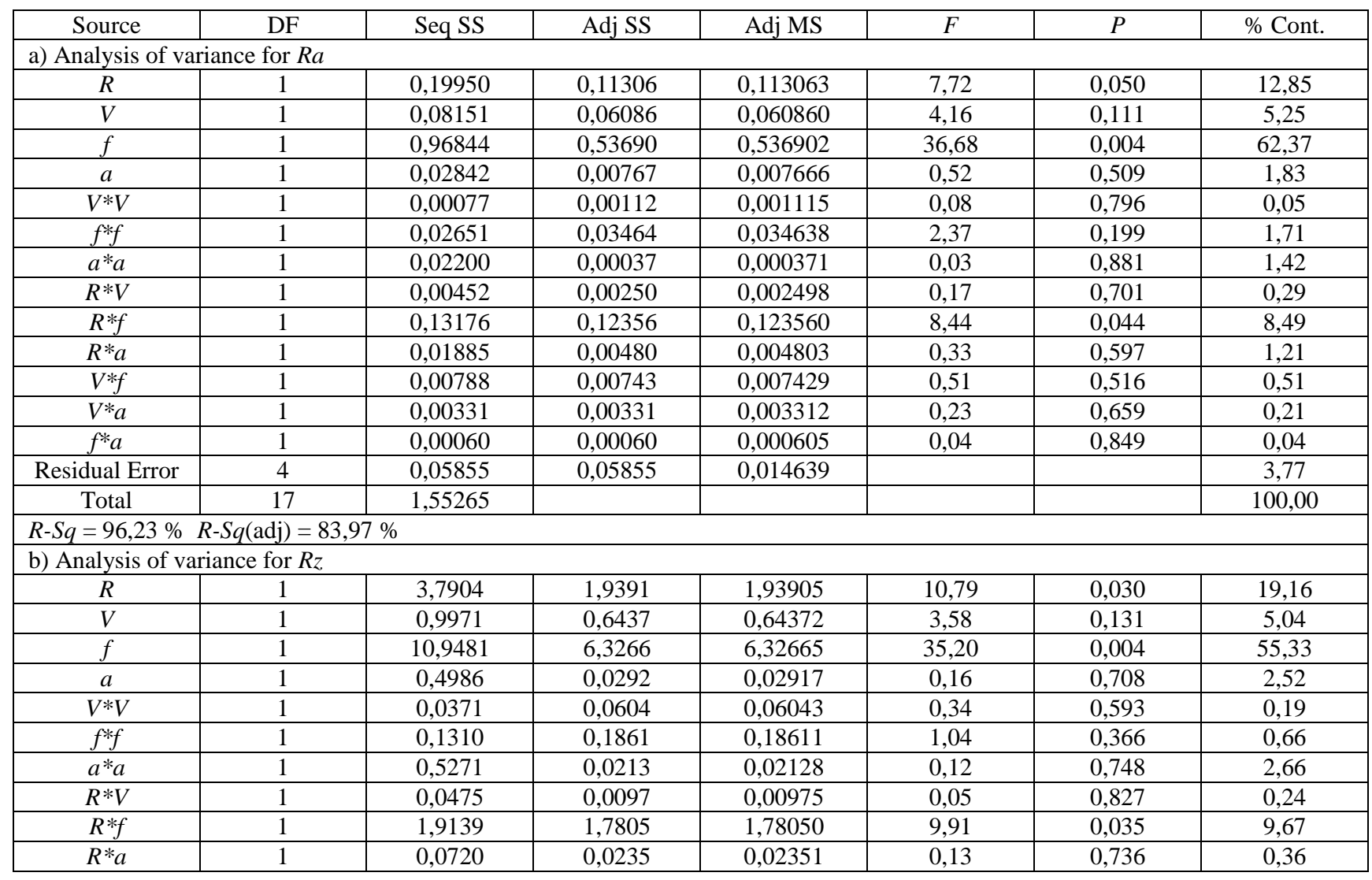




\begin{tabular}{|c|c|c|c|c|c|c|c|}
\hline Source & DF & Seq SS & Adj SS & Adj MS & $F$ & $P$ & $\%$ Cont. \\
\hline$V^{*} f$ & 1 & 0,0040 & 0,0053 & 0,00526 & 0,03 & 0,872 & 0,02 \\
\hline$V^{*} a$ & 1 & 0,0492 & 0,0492 & 0,04923 & 0,27 & 0,628 & 0,25 \\
\hline$f^{*} a$ & 1 & 0,0509 & 0,0509 & 0,05095 & 0,28 & 0,623 & 0,26 \\
\hline Residual Error & 4 & 0,7189 & 0,7189 & 0,17973 & & & 3,63 \\
\hline Total & 17 & 19,7859 & & & \\
\hline$R$-Sq=96,37 \% $R$-Sq(adj) $=84,56 \%$ \\
\hline c) Analysis of variance for $R t$ \\
\hline R
\end{tabular}

Fig. 6 and Fig. 7 show the comparative graphs of the simulation $R a, R z$ and $R t$ results and the $F x, F y$ and $F z$ test results obtained by experimental and RSM. When the figures were examined, it was observed that the experimental and simulation results were compatible with each other. Fig. 5 shows the $F x, F y$, and $F z$ values increased with the increased feed rate and depth of cut. Along with the increasing feed rate, the increase of cutting force required for the chip formation due to increasing chip cross section and indirectly the increase of $F x, F y$ and $F z$ are an expected result (Fig. 5, a, Fig. 5, b and Fig. 5, c). On the other hand, there was no significant increase in $F x, F y$ and $F z$ values as tool tip radius increased. This result refers to the entering angle decreasing with the increase of the $R$, which is in parallel with the knowledge that the increase in $R$ will mainly affect the $F x[28,29]$. In addition, it was observed that $F x, F y$ and $F z$ did not tend to increase with the increase of cutting tool radius. The reason for this can be shows as the difference of cutting speed in the experiments carried out for the same feed rate. Furthermore, Table 8-Table 10 and Fig. 5 show that cutting speed did not significantly affect the cutting forces.

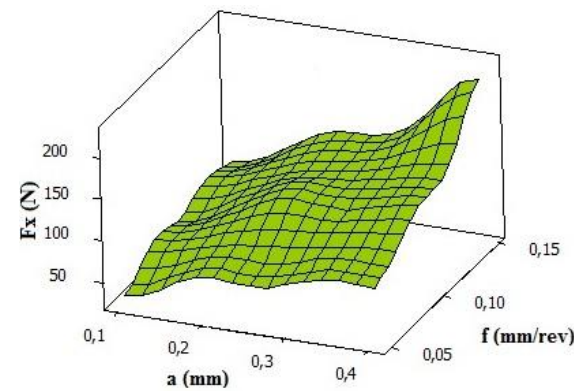

$\mathrm{a}$

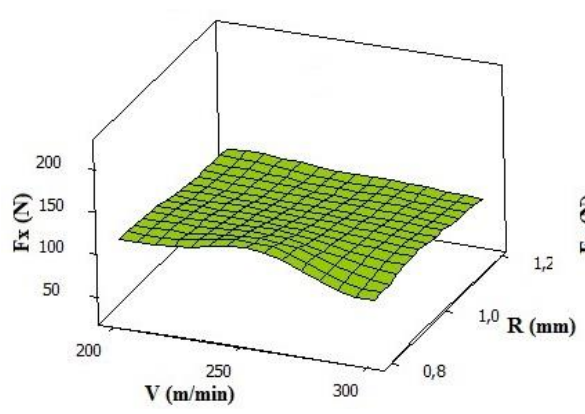

d

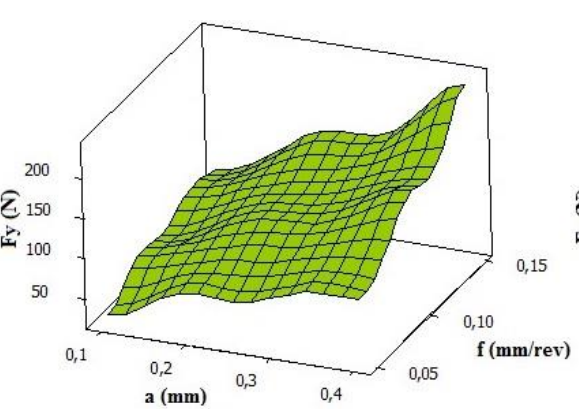

b

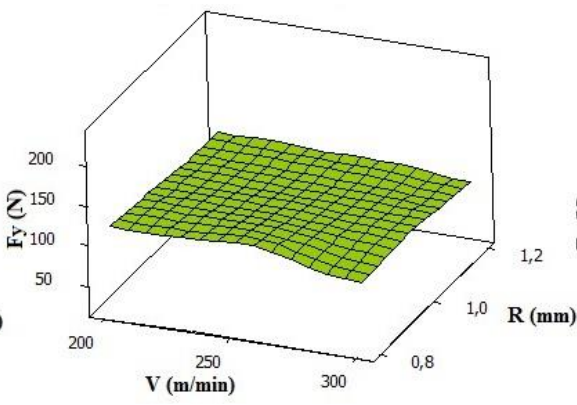

e

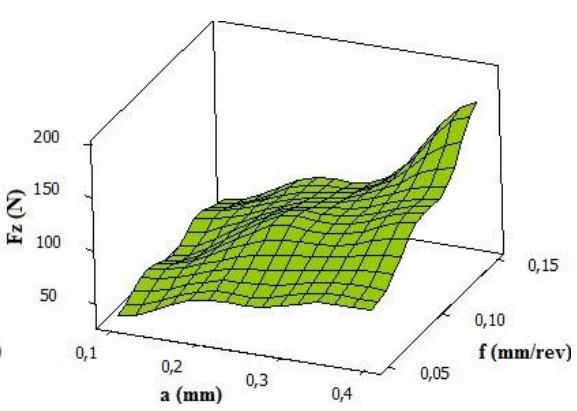

c

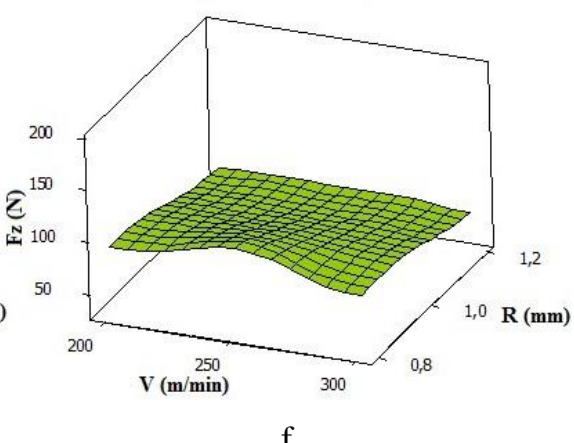

$\mathrm{f}$

Fig. 5 Effect of machining parameters on $F x, F y$ and $F z$

The relationship between the surface roughness and machining parameters such as cutting speed $V$, feed $f$, depth of cut $a$ and tool nose radius $R$ for second order response surface model has been developed using RSM from 
the observed data in uncoded units as follows. The predicted actual uncoded factors, i.e., $R a, R z$ and $R t$ was calculat- ed using Eqs. (2) - (4) and cutting forces of Eqs. (5) - (7).

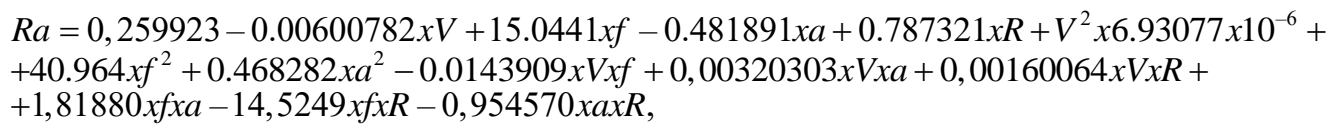

Optimal results of $R a, R z$, and $R t$ and $F x, F y$ and $F z$ values were obtained in the experimental study conducted by using Taguchi optimization method and the percentage distribution of the parameters affecting the result was determined with ANOVA analysis. The final step of the optimization process is the conduction of the validation tests and testing the validity of the optimization process. As a result of the Taguchi optimization, the parameter group giving the optimal $R a, R z$, and $R t$ and $F x$, $F y$ and $F z$ could sometimes be any of the current tests; whereas, it may sometimes be an experiment other than the tests. In the study, the validation tests were repeated 3 times other than the current tests with the cutting parameters of $V 2-f 2-a 2-R 2(V=250 \mathrm{~m} / \mathrm{min}, f=0.1 \mathrm{~mm} / \mathrm{rev}$, $a=0.25 \mathrm{~mm}$ and $R=1.2 \mathrm{~mm}$ ) for $R a, R z, R t$ and $V 1-f 2-a 1-$ $R 1(\mathrm{~V}=200 \mathrm{~m} / \mathrm{min}, f=0.1 \mathrm{~mm} / \mathrm{rev}, \quad a=0.05 \mathrm{~mm}$ and $R=0.8 \mathrm{~mm}$ ) for $F x, F y$, and $F z$ and the arithmetic means were collected. As a result of validation tests, Table 13 shows that high convergence values were obtained in the experimental results with the estimated results. In this context, it was noteworthy that the difference between the validation test results and those obtained from Taguchi approach was negligible.

Comparison of the prediction model and experimental results

Table 13

\begin{tabular}{|c|c|c|c|c|c|c|c|}
\hline Parameters & Parameters Levels & \multicolumn{2}{|c|}{ Values of $R a, \mu \mathrm{m}$} & \multicolumn{2}{|c|}{ Values of $R z, \mu \mathrm{m}$} & \multicolumn{2}{|c|}{ Values of $R t, \mu \mathrm{m}$} \\
\hline$V, \mathrm{~m} / \mathrm{min}$ & 250 & Prediction & Experimental & Prediction & Experimental & Prediction & Experimental \\
\hline$f, \mathrm{~mm} / \mathrm{rev}$ & 0.1 & \multirow{3}{*}{0.2928} & \multirow{3}{*}{0.3228} & \multirow{3}{*}{1.7344} & \multirow{3}{*}{1.8927} & \multirow{3}{*}{1.8016} & \multirow{3}{*}{1.9087} \\
\hline$a, \mathrm{~mm}$ & 0.25 & & & & & & \\
\hline$R, \mathrm{~mm}$ & 1.2 & & & & & & \\
\hline & & \multicolumn{2}{|c|}{ Values of $F x, \mathrm{~N}$} & \multicolumn{2}{|c|}{ Values of $F y, \mathrm{~N}$} & \multicolumn{2}{|c|}{ Values of $F z, \mathrm{~N}$} \\
\hline$V, \mathrm{~m} / \mathrm{min}$ & 250 & \multirow{4}{*}{104.8719} & \multirow{4}{*}{99.1089} & \multirow{4}{*}{112.8485} & \multirow{4}{*}{115.8965} & \multirow{4}{*}{75.8351} & \multirow{4}{*}{79.3597} \\
\hline$f, \mathrm{~mm} / \mathrm{rev}$ & 0.1 & & & & & & \\
\hline$a, \mathrm{~mm}$ & 0.25 & & & & & & \\
\hline$R, \mathrm{~mm}$ & 1.2 & & & & & & \\
\hline
\end{tabular}

\section{Conclusions}

In this study, the effects of different cutting speed, feed rate, depth of cut and tool tip radius on $R a, R z$ and $R t$ and $F x, F y$ and $F z$ in the turning of hardened $42 \mathrm{CrMo} 4$ steel were investigated. The following results were obtained as a result of the study where Taguchi method was used in the optimization of machining parameters.

$>$ According to the results of variance analysis of $S / N$ ratios, the significance rank of the variables that were effective on $R a, R z$ and $R t$ was determined as $f, R, V$ and ap. In the optimization made with the help of $S / N$ analysis, it was observed that the optimum machining parameters giving the lowest $R a, R z$ and $R t$ value $(R a=0.184 \mu \mathrm{m}, R z=1.273 \mu \mathrm{m}$ and $R t=1.397 \mu \mathrm{m})$ were $V 3-f 3-a 2-R 1$ for $R a$; whereas, they were $V 3-f 1-a 1-R 2$ for $R z$ and $R t$.

When ANOVA results were examined, it was determined that $f$ was the most effective parameter on $R a, R z$ and $R t$ with the rates of $62.37 \%, 55.33 \%$ and $50.96 \%$ and then $R$ contributed to $R a$ by $12.85 \%, R z$ by $19.16 \%$ and $R t$ by $18.58 \%$. When the effect of cutting parameters on surface roughness was examined in terms of $P$ significance value $(p<0.05)$, it was determined that while $V$ and $a$ were not significant, $f$ and $R$ were significant. 
In cutting tests, the surface roughness values increased with the increasing $f$, whereas, it decreased as $R$ increased. It was found that there was a direct correlation between the feed rate and the surface roughness.

$>$ When $S / N$ ratios of cutting parameters on $F x, F y$ and $F z$ were examined, it was determined that the most effective parameter was $a$, the second one was $f$ followed by $V$ and $R$. Optimum machining parameters were $V 3-f 1-a 1-R 2$ for $F x$ and $F z$ cutting forces and $V 3$ $f 1-a 1-R 1$ for $F y$.

$>$ It was determined that as $f$ and $a$ increased, $F x, F y$ and $\mathrm{Fz}$ increased, they tended to decreased with the increase of $V$ but they did not show any change with the increase of $R$.

$>$ As a result of ANOVA analysis, it was determined that $a$ and $f$ contributed by $53.48 \%$ and $33.21 \%$ on $F x$, $56.63 \%, 36.18$ and $63.47 \%, 14.22 \%$ on $F y$ and $F z$, respectively. $R$ and $V$ were effective by the rates of $3.88 \%$ and $2.28 \%$ on $F x, 1.52 \%$ and $1.21 \%$ on $F y$, and 12.40 and $0.45 \%$ on $F z$.

$>$ As a result of the validation tests, when the estimated results and experimental results were compared, high convergence values were obtained with the rates of $90.7 \%$ in $R a, 91.63 \%$ in $R z, 94.38 \%$ in $R t, 94.50 \%$ in $\mathrm{Fx}, 97.37 \%$ in $\mathrm{Fy}$ and $95.55 \%$ in $\mathrm{Fz}$.

\section{References}

1. Karayel, B.; Nalbant, M. 2014. Effects of feed rate, cuttıng speed and cuttıng tools on average surface roughness, tool life and wear in turnıng of AISI 4140 material, Electronic Journal of Machine Technologies 11: 11-26.

2. Çakmak, S.; Sarıdemir, S. 2016. The effect of insert geometry on chip breaking and surface roughness in machining of AISI 4140 steel, Düzce Üniversitesi Bilim ve Teknoloji Dergisi 4: 765-771.

3. Chaouch, D.; Guessasma, S.; Sadok, A. 2014. Finite element simulation coupled to optimisation stochastic process to assess the effect of heat treatment on the mechanical properties of $42 \mathrm{CrMo} 4$ steel, Materials \& Design 34: 679-684.

4. Özçatalbaş, Y., 2002. The effects of tool wear and mechanical properties of workpiece material on surface roughness and cuttıng forces, Journal of Polytechnic 4: 47-52.

5. Çakır, C. 1999. Modern talaşlı imalatın esasları, Uludağ Üniversitesi Güçlendirme Vakfı Yayınları, Bursa 140: 1-110.

6. Akkurt, M. 2004. Talaş kaldırma yöntemleri ve Takım tezgâhları, Birsen Yayın Evi, Istanbul.

7. Ozel, T.; Hsu, T. K.; Zeren, E. 2005. Effects of cutting edge geometry, workpiece hardness, feed rate and cutting speed on surface roughness and forces in finish turning of hardened AISI H13 steel, Int J Adv Manuf Technol 25: 262-269. https://doi.org//10.1007/s00170-003-1878-5.

8. Panzera, T. H.; Souza, P. R.; Rubio, J. C. C.; Abrao, A. M.; Mansur, T. R. 2012. Development of a threecomponent dynamometer to measure turning force, The International Journal of Advanced Manufacturing Technology 62: 913-922. https://doi.org//10.1007/s00170-011-3866-5.
9. Singh, D.; Rao, P. V. 2007. A surface roughness prediction model for hard turning process, International Journal of Machine Tools \& Manufacture 32: 11151124.

10. Jayant, A.; Kumar, V. 2008. Prediction of surface roughness in CNC turning operation using Taguchi design of experiments, Journal of the Institution of Engineers, Production Engineering Division 88: 19-25.

11. Derakhshan, E. D.; Akbari, A. A. 2009. Experimental investigation on the workpiece hardness and cutting speed on surface roughness in hard turning with CBN tools, Proceedings of the World Congress on Engineering, Volume II.

12. Chavoshi, S. Z., Tajdari, M., 2010. Surface roughness modelling in hard turning operation of AISI 4140 using CBN cutting tool, International Journal of Material Forming. https://doi.org/10.1007/s12289-009-0679-2.

13. Aouici, H.; Yallese, M. A.; Fnides, B.; Mabrouki, T. 2010. Machinability investigation in hard turning of AISI H11 hotwork steel with CBN tool, Mechanika 86: 71-77.

14. Suresh, R.; Basavarajappa, S.; Gaitonde, V. N.; Samuel, G. L. 2012. Machinability investigations on hardened AISI 4340 steel using coated carbide insert, Int. J. Refract. Metals Hard Mater 33: 75-86.

15. Abou-El-Hossein, K. A.; Kadirgama, K.; Hamdi, M.; Benyounis, K. Y. 2007. Prediction of cutting force in end-milling operation of modified AISI P20 tool steel, Journal of Materials Processing Technology 182: 241-247.

16. Yang, A.; Han, Y.; Pan, Y.; Xing, H.; Li, J. 2017. Optimum surface roughness prediction for titanium alloy by adopting response surface methodology, Results in Physics 7: 1046-1050. https://doi.org/10.1016/j.rinp.2017.02.027.

17. Asilturk, I.; Akkus, H. 2011. Determining the effect of cutting parameters on surface roughness in hard turning using the Taguchi method, Measurement 44: 1697-1704. https://doi.org/10.1016/j.measurement.2011.07.003.

18. Günay, M.; Yücel, E. 2013. Application of Taguchi method for determining optimum surface roughness in turning of high-alloy white cast iron, Measurement 46: 913-919. https://doi.org/10.1016/j.measurement.2012.10.013.

19. Bouacha, K.; Yallese, M. A.; Mabrouki, T.; Rigal, J. F. 2010. Statistical analysis of surface roughness and cutting forces using response surface methodology in hard turning of AISI 52100 bearing steel with CBN tool, Int. Journal of Refractory Metals \& Hard Materials 28: 349-361. https://doi.org/10.1016/j.ijrmhm.2009.11.011.

20. Lalwani, D. I.; Mehta, N. K.; Jain, P. K. 2008. Experimental investigations of cutting parameters influence on cutting forces and surface roughness in finish hard turning of MDN250 steel, Journal of Materials Processing Technology 206: 167-179. https://doi.org/10.1016/j.jmatprotec.2007.12.018.

21. Agrawal, A.; Goel, S.; Rashid, W. B.; Price, M. 2015. Prediction of surface roughness during hard turning of AISI 4340 steel (69 HRC), Applied Soft Computing 30: 279-286. https://doi.org/10.1016/j.asoc.2015.01.059. 
22. Taguchi, G.; Konishi, S. 1987. Orthogonal Arrays and Linear Graphs, American Supplier Institute.

23. Taguchi, G.; Elsayed, E.; Hsiang, T. 1989. Quality Engineering in Production Systems, McGraw-Hill, Books, New York, 235-241.

24. Köklü, U. 2013. Optimization of machining parameters in interrupted cylindrical grinding using the Greybased Taguchi method, International Journal of Computer Integrated Manufacturing 26: 696-702. https://doi.org/10.1080/0951192X.2012.749537.

25. Özdemir, M. 2019. Optimization with Taguchi method of influences on surface roughness of cutting parameters in CNC turning processing, Mechanika 25: 397405. https://doi.org/10.5755/j01.mech.25.5.23005.

26. Korkut, I.; Boy, M.; Karacan, I.; Seker, U. 2007. Investigation of Chip-back temperature during machining depending on cutting parameter, Materials and Design 28: 2329-2335. https://doi.org/10.1016/j.matdes.2006.07.009.

27. Outeiro, J. C.; Umbrello, D.; M'Saoubi, R. 2006. Experimental and numerical modelling of the residual stresses induced in orthogonal cutting of AISI 316L steel, International Journal of Machine Tools and Manufacture, 46; 1786-1794. https://doi.org/10.1016/j.ijmachtools.2005.11.013.

28. Çiftçi, İ.; Gökçe, H. 2019. Optimisation of cutting tool and cutting parameters in machining of molybdenum alloys through the Taguchi Method, Journal of the Faculty of Engineering and Architecture of Gazi University $34: 201-213$.

29. Kurt, A.; Seker, U. 2005. The effect of chamfer angle of polycrystalline cubic boron nitride cutting tool on the cutting forces and the tool stresses in finishing hard turning of AISI 52100 steel, Materials and Design 26: 351-356. https://doi.org/10.1016/j.matdes.2004.06.022.
M. Özdemir, M.T. Kaya, H.K. Akyildiz

\section{ANALYSIS OF SURFACE ROUGHNESS AND CUTTING FORCES IN HARD TURNING OF 42CrMo4 STEEL USING TAGUCHI AND RSM METHOD}

S u m m a r y

In this study, cutting speed $V$, feed rate $f$, depth of cut $a$ and tool radius $R$ of surface roughness $R$ of hardened 42CrMo4 (52 HRC) material with ceramic insert having different $R a, R z$ and $R t$ ) and cutting forces (Radial force $F x$ effect) tangential force $F y$ and feed force $F z$ were investigated experimentally. For the experimental design, Taguchi's mixed-level parameter design (L18) was used $(2 \times 1.3 \times 3)$. Signal-to-noise ratio $S / N$ was used to evaluate the test results. Using the Taguchi method, cutting parameters and cutting forces giving optimum surface roughness were determined. Regression analysis is applied to predict surface roughness and cutting forces. ANOVA was used to determine the effects of machining parameters on surface roughness and cutting forces. According to ANOVA analysis, the most important cutting parameters were found to be the cutting depth between feed rate and cutting forces for surface roughness. Verification experiments were performed and it was observed that optimization was applied successfully.

Keywords: machining, taguchi method, analysis of variance, cutting parameters.

Received June 18, 2019

Accepted June 02, 2020 